\title{
Instructional Goal Structure, Gender, and Second Language Motivation Affecting English Language Achievement
}

\author{
Lemecha Geleto Wariyo \\ Addis Ababa University
}

\begin{abstract}
Correspondence concerning this article should be addressed to Lemecha Geleto Wariyo, Department of Curriculum and Instruction, Addis Ababa University, NBH1, 6killo King George VI St, Addis Ababa, Ethiopia. E-mail: lemechageleto@yahoo.com
\end{abstract}

\begin{abstract}
The study opted to: 1) Investigate differences between cooperative and competitive learning modes in the extent to which they affect English language achievement; 2) Find gender, intragender, and inter-gender differences in English language achievement within and across the cooperative, competitive, and control group learning conditions; and 3) Study the relationship between students' motivation to learn the English language and English language achievement. The cooperative and competitive learning groups were used as treatment groups while the control group was the individualized learning group. An English language test was administered to 120 secondary school grade nine students. The 12-item mini-Attitude/Motivation Test Battery (Mini-AMTB) was administered to the students. Different parametric tests were used in the pre-test and post-test data analysis. Post-test data analysis results revealed that cooperative learners significantly outperformed both competitive learners and the control group, but the control group significantly outperformed competitive learners. The gender difference in English language achievement was not significant. The cooperative learning (CL) mode was favored by both male and female students but more favored by males. The five aggregate measures of the mini-AMTB (Integrativeness, Motivational Intensity, Attitudes towards the Learning Situation, Instrumental Orientation, and Parental Encouragement) produced significant positive correlations with English language achievement; however, Language Anxiety negatively and significantly correlated with English language achievement. The CL mode, with its effective CL technique, was recommended to be researched and applied by trained teachers to improve student achievement. Its implications for teacher training were also given. Treatment of second language motivation was recommended as an important issue in second language learning.
\end{abstract}

Keywords: cooperative learning, competitive learning, instructional goal structure, second language motivation

\section{Introduction}

Cooperative learning (CL) results in highest student achievement and good pro-social behavior, as well as attitudes toward learning and higher-order reasoning (Alghamdy, 2019; Gillies, 2016; Johnson, Johnson, Roseth, \& Shin, 2014; Peldon \& Chalermnirundorn, 2018; Sharan, 1980; Yager, Johnson, \& Johnson, 1985; Zarei, 2012; Zhang, 2010). Kyndt and et.al (2013) also reported that CL positively affects achievement and attitudes. As a modern pedagogy, CL is a method that has a significant positive effect on achievement, motivation to learn, group cohesion, critical thinking, and problem-solving (Baloche, \& Brody, 2017). CL is effective because it uses an active learning approach between learners of heterogeneous abilities and backgrounds (Azizinezhad, Hashemi, \& Darvishi, 2013, Ghodbane \& El Achachi, 2019).

When it comes to language learning, current language teaching methodologies emphasize both communication and the learner (Lopez \& Rua, 2006; Oxford, 1997). The CL methodology has attracted practitioners of communicative language teaching because of the innovative methodologies it applies in the language classroom (McCafferty, Jacobs, \& Iddings, 2006). 
In Ethiopian schools, a student-centered teaching approach was introduced decades ago. The Institute for Curriculum Development and Research, Ministry of Education, has prepared new English language textbooks for high schools (Gezahegn, 2003). Gezahegn also stated that the course is more student-centered and communicative than its predecessors. Even though this teaching approach has been applied in schools, problems related to its implementation have been reported (Lucha \& Bongase, 2015; Kumar, 2017; Moges, 2019; Reda \& Hagos, 2015; Serbessa, 2006; Yayo, 2013). Tirussew, Amare, Jeilu, Tassew, Aklilu, and Berhannu (2018) found that the implementation of CL through the Education Development Army has been found to be poor, contrary to its positive effects on student learning as confirmed by studies from around the world.

In addition to the language teaching-learning approach, gender difference has become a hot topic of discussion in language studies. The empirical gender research in the field of second language learning underlies gender differences and the role of gender in second language learning (Feery, 2008). Second language education and the field of gender has a long history, and it has been a burning issue for language researchers and teachers since the outbreak of the women's movement (Sunderland, 2010). Gender is an issue that has significant implications in second language learning. Gender difference theories state that females use learning strategies more effectively (Tercanlioglu ${ }^{1}$, 2004). In the Ethiopian context, the gender differences in English language achievement have been inadequately researched. To identify gender-related factors that contribute to under-achievement, local empirical studies on gender differences in language achievement are needed.

Even nowadays, research findings on gender differences in second language achievement show that female performance dominates male performance. Van Der Slik, van Hout, and Schepens (2015) studied gender differences across countries and language families in the world, using a dataset consisting of 27,119 adult Dutch learners as a second language. In this study, female students repeatedly outperformed male students in writing and speaking proficiency. Mady and Seiling (2017) also found that being female was associated with increases in French achievement. Females in some parts of the world may have better opportunities and psychosocial differences than females from other parts of the world. As a result, the natural advantages for females in learning may be biased due to these factors. For this reason, a critical approach to this topic is paramount. However, taking a critical and contextual approach to gender differences in language achievement is a recent phenomenon. Supporting this, Schmenk (2004) stated that gender difference positions in previous research to understand gender and language learning were culture blind because they regarded gender as an unchanging, contextually independent variable. Studies stereotype language performance as a female's domain and mathematics performance as a male's domain. The cultural, economic, and other local factors that may affect females' achievement ought to be controlled to arrive at more valid conclusions regarding subject area difference between sexes.

Furthermore, gender differences in the modes of language learning are another issue that has been discussed in recently conducted studies around the world (Alsheikh \& Elhoweris, 2011; Esiobu, 2011; Hossain, Tarmizi, Aziz and Nordin, 2013; Mohammadjani, \& Tonkaboni , 2015;). Studying intra-gender differences in English language achievement across the three learning conditions was another objective of this study. In other words, the study opted to analyze the differences between same-sex learners in English language achievement across the three learning conditions. By doing this, the study aimed at analyzing a learning mode that results in significantly higher achievement for both a female same-sex group of learners and a male same-sex group of learners that are compared to their peer same sexes ( e.g., assume that both female and male cooperative leaners outperform their same-sex groups in other learning conditions). This implies that cooperative learning is favoured by both sexes because it works best for both sexes when compared to their own peer same-sex groups. Previous studies on learning modes did not consider these issues in the Ethiopian context. The researcher believes this issue can help educators obtain more information on how males and females learn.

Moreover, another variable that received attention in previous studies for affecting students' second language achievement is second language motivation. In a meta-analysis that explained seventy-five different samples consisting of 10,489 participants, the findings revealed that the correlations between motivation and achievement were consistently and similarly higher than the correlations of the other variables, such as integrativeness, instrumental orientation, and attitudes toward the learning situation with student achievement (Masgoret \& Gardner, 2003). The Socio-Educational Model (Gardner, 2005) proposed that motivation and situational anxiety

\footnotetext{
${ }^{1}$ L., T. (n.d.). IIER 14: Tercanlioglu - gender effect on adult foreign language learning [Web logpost]. http://www.iier.org.au/iier14/tercanlioglu.html
} 


\section{LEMECHA GELETO WARIYO}

are more important in second language learning. Female students' integrative motivation and attitudes towards the English language are higher than male students (Al Harthy, 2017). A large scale meta-analytic study by Teimouri, Goetze, and Plonsky (2019) reported a strong significant association between language anxiety and second language achievement.

In Ethiopia, although there is a shortage of studies on the associations between second language motivation and second language performance, two studies by Gezahegn (2003) and Kumar (2017) reported that students' low motivation, language anxiety, and poor proficiency in the English language were identified as impediments to the implementation of group work in English language teaching classes. This report runs counter to previous studies that argued that when teachers use CL effectively in language study classrooms, the learners' motivation to learn the language is heightened (Johnson, Johnson, Roseth, \& Shin, 2014; Zareian \& Jodaei, 2015).

\section{Statement of the Problem}

Contrary to a myriad of findings that support the positive effects of CL on students' performance, the findings in Ethiopian schools on the effectiveness of CL are still controversial. A study by Gezahegn (2003) revealed that teachers' resistance to the new instructional procedure is most likely to be attributed to their lack of adequate training and skills necessary to devise and manage group-work activities. Despite the arguments against the teacher-centered methodology in education, the teaching-learning process in most schools in Ethiopia has continued to be teacher-centered (Desta, Chalchisa, Mulat, Berihum, \& Tesera, 2009). The major factors impacting the implementation of active learning in Ethiopia are teachers' shortage of skills, an unsuitable curriculum and resources for CL, learners' shortage of prior experience to actively cooperate in the learning process, inappropriate classroom materials, a shortage of language proficiency, shyness, and the lack of skill to use various CL methods (Ayele \& Olamo, 2019; Lucha \& Bongase, 2015; Serbessa, 2006; Yalew, 2004; Yayo, 2013).

Generally, studies report that the responsibility for the effective application of CL is shared by students and teachers (Ferguson-Patrick, 2016). According to Gillies (2016), teachers are the leaders in organizing and facilitating CL activities in classrooms. Learners' attitudes toward the cooperative method has caused problems in applying this approach with students (Çelik, Aytın, \& Bayram, 2013). Although the effectiveness of CL was well recorded, applying it in classrooms is a challenge for many teachers (Gillies, Ashman, \& Terwel, 2007; Jolliffe, 2019). Commonly used group-work activities with language teaching are dissimilar to CL. Although group work, such as role-playing and problem-solving activities are prerequisites to CL and consist of certain CL principles, CL tasks in second language classrooms usually underutilize CL principles (Siciliano, 2001).

Because language is a key to academic success, the underutilization of the student-centered teaching methods can result in low language proficiency and this can be a factor in academic failures. Concerning this issue, a recent study published in Ethiopia by Reda and Hagos (2015) reported that there is a shortage of skills and knowledge in using CL principles and structure in elementary schools in Ethiopia. These researchers pointed to the problem. However, the study warrants focusing on how the existing implementation problems can be solved. Therefore, conducting empirical studies on how to utilize appropriate student-centered techniques (i.e., CL techniques and principles in this study) and ways to motivate teachers and students toward the method is very important.

Another gap in language research in Ethiopia is a shortage of studies on gender differences in language achievement, although it has received a great deal of attention in many studies around the world. In the Ethiopian educational context, a critical study on gender differences in second or foreign language learning is also crutial. This may help in dealing with gender-related learning problems. Observing favorable learning modes for males and females is also an important issue for designing effective instructional methods.

Therefore, this study is primarily opted to: 1) Find the differences between the three learning conditions (cooperative, competitive, and individualistic learning) in English language achievement; 2) Analyze gender differences in English language achievement; 3) Find the correlations between the aggregate measures of the mini-AMTB and the English language achievement; 4) Analyze gender differences in English language achievement within a group of students who learn using similar learning modes; and 5) Find the learning mode that is most favorable for both males and females. 
The following research questions were formulated to achieve the objectives of this study: A) Do groups of students who learn using cooperative and competitive learning modes significantly differ in English language achievement? B) Is the gender difference in English language achievement significant? C) Is there a significant gender difference in English language achievement within a group of students who learn using a similar learning mode? D) Which learning mode is significantly favored by both males and females? E) Is there a significant correlation between the aggregate measures of the mini-AMTB and English language achievement?

\section{Theoretical Framework}

CL is the use of small groups in which the learners study together to enhance their own and their peers' learning (Boling \& Robinson, 1999; Johnson and Johnson, 1974; Johnson, Johnson, \& Holubec, 2013; W. Johnson, \& T. Johnson, 2018). Goal structure (i.e., learning mode) is an interdependence that exists among students and how the students will interact with one other and with their teacher in studying toward the achievement of learning objectives (Johnson, \& Johnson, 2013; W. Johnson, \& T. Johnson, 2018; Owens \& Straton, 1980). These authors listed three different conditions of interdependence: 1) A cooperative goal structure exists in a learning situation in which students can achieve their own individual learning goals only through studying with their group as they achieve their learning goals; 2) Competitive goal structures exist in a learning situation in which learners are able to achieve their own individual learning objectives only through causing others fail to achieve their own learning goals; and 3) An individualistic learning goal structure happens in a learning situation in which learners work to achieve their own individual learning goals regardless of what other students choose to work on to achieve their individual goals. CL can be defined as a learning method in which learners work in small groups to enhance their team's learning (Slavin, 2014). Generally, the definitions view CL as a learning approach in which all group members work toward achieving an individual goal through achieving a group goal by supporting one another. On the other hand, they defined competitive learning as a learning approach in which individual students compete to outperform others to achieve their own individual goals. In individualistic learning, students are neither inclined to support one another nor compete to outperform others to achieve their own goal. It is assumed that their achievement depends on their own efforts.

According to Deutsch's cooperative-competitive theory (1949, 2011, \& 2015), a competitive social situation is a social situation in which the objectives of various participants are associated to the point that they result in a negative association between their individual accomplishments. Deutsch pointed out that the student seeks not only to succeed but also to cause other students to fail in a competitive situation; the student emphasizes the outcome that is most useful for them and most problematic to their peers. According to Deutsch, an individualistic situation is one where the goals of the individuals are unrelated. Deutsch suggested that the instructional method applied ought to be in the form of a CL method that takes the form of the conflictual and controvercial interactions in the classroom in order to facilitate the development of conflict resolution skills.

Corresponding to cooperation-competition theory- Teams-Games Tournament (TGT) is a structured blend of educational techniques such as small groups, educational games, and tournaments that apply encouragement for successful academic performance.

The TGT consists of both cooperation and competition in a way that enhances peer-group rewards for academic performance. This happens through changing the social organization of the class as follows: 1) Creating interdependence between learners; and 2) Making it possible for all learners to have an equal probability of being successful in a project regardless of various learning rates (Slavin, 1995, 2014). Another study by Slavin (2013) revealed that well-structured CL methods bring about more positive effect sizes than the use of innovative curriculum textbooks or the use of technology in maths. The carefully structured CL techniques, with which are easier for both experienced and inexperienced teachers to apply the principles of CL in the classroom, have to be carefully researched before being included in the Ethiopian curriculum.

On the other hand, similar to its application in sports, cooperation-competition has an effective application in learning classrooms. It is possible to replace interpersonal (individualistic) competition in the classroom with a competition between groups, accompanied by a competition within a group. By incorporating educational materials into intellectual games, learning can be like a sport. The students' interest and motivation toward learning can be heightened in this way (Slavin, 1991; Slavin, 1995, Slavin, 2014). 
Nevertheless, making students work in groups can be quite beneficial or it can hold little value. Its effectiveness depends on how it is implemented in classroom settings. Two kinds of CL techniques were identified: 1) Structured Team Learning, which is characterized by individual accountability. Individual accountability implies that the success of a team depends on individual learning and rewards to the groups are dependent on the learning progress of their members; and 2) Informal Group CL approaches are more focused on social dynamics and discussion (Pedersen \& Digby, 2014; Slavin, 1991). In order to conform to 'the how' issue of implementing CL in the classroom, in this study, a structured CL model (Teams-Games-Tournament) was implemented.

In addition to Slavin's work, Johnson and Johnson (2013) listed four CL types: informal, formal, cooperative base groups and constructive controversy. When CL types are categorized by their objectives, formal CL groups are often used to teach specific content; informal $C L$ groups are used to accelerate the active processing of cognition while teaching students; cooperative base groups are often used to deliver long-term support for academic progress; and constructive controversy can also be used as a method of involving intellectual conflicts in the learning process.

\section{Cooperative Learning Principles according to Slavin}

Effective CL should encompass six principles: 1) Positive Interdependence implies that an increase in learning for one person is correlated with an increase in learning for other group members.This situation of learning is created through structuring the goals, materials, and rewards; 2) In assuring accountability, each student becomes accountable through testing and grading. Through the group grade, the group becomes accountable; 3 ) Team Formation is accomplished randomly by learner interest and by using criteria such as homogeneity, gender, and aptitude; 4) Team Size: A team works best when it is smaller than seven members; 5) Cognitive Development: It is the main objective of CL; and 6) The next CL principle is Social Development in which the development of social skills, such as turn-taking and active listening, are achieved (Slavin, 1991; Slavin, 1994; Slavin, 1995).

Slavin seemed to be concerned about the difficulties and problems implementing CL by teachers and students around the world. As a result, in his recent work, Slavin (2014) stated that teachers can gain the highest benefit from CL by using these five strategies and they can ensure that collaboration: 1) Enhances the development of communication and problem-solving skills; 2) Creates interdependent teams; 3) Sets group goals; 4) Ensures individual accountability; and 5) Integrates CL with other structures of learning.

\section{Cooperative Learning Principles According to Johnson and Johnson}

These authors pointed out that in order to enhance the effectiveness of the CL, groups have to be formed so that the five elements of the effective cooperative method are included in their structure: 1) Creating Positive Interdependence in the learning procedure, thereby each of the students in a group understands that they are associated in such a way that individual success depends on the group success; 2) Promotive Interaction: It is about encouraging others to accomplish each other's tasks to help the team achieve its objective. This interaction is enhanced when students support each other when needed; when members share resources, give each other effective feedback on specific activities, critically analyze one another's conclusions and reasoning, and work in cooperation to achieve common objectives; 3) These authors describe Individual Accountability as a learner's responsibility in ensuring that they accomplish their part of work while ensuring that one's peers accomplish theirs. Accountability is promoted by i) Creating positive interdependence between each member, thereby making them responsible for leading peer activities; ii) Making group members individually accountable for working on their part in the activity and making sure that their activities can be clearly recognized; 4) Negotiation with Older Students and Teaching the Younger Students the Important Interpersonal Skills to manage conflict between individual group members is highly crucial; 5) In the Group Processing, students reflect on their own performance and their own work interactions by asking what they achieved, by asking each other what they haven’t achieved, and what they need to do?” (Gillies, 2016; Johnson, \& Johnson, 2017).

\section{Teams-Games-Tournament (TGT)}

In TGT, the teacher assigns students to four- or five-member groups. A cross-section of academic ability levels in the class has to be shown in the group composition. This should also be applied to representatives of ethnic groups and sex groups. The objective of this grouping is to make its members ready through peer tutoring and 
practice for the following day's tournament by working on the material presented by the teacher. The teaching activity is delivered in any method a teacher is accustomed to using. A tournament usually takes forty minutes, is held once per week, and consists of short-answer questions from the material (Slavin, 1980; Slavin, 1991; Slavin, 1995; Slavin, \& Project, 1994).

Three students of homogeneous academic performance are assigned to tournament tables based on the previous performance in the same subject. After the game has ended, the three competitors are ranked and given marks or points (the highest performer in each group earns six points, the middle performer earns four points, and the lowest performer earns two points). The group scores (i.e., the score of the original practice group or team of four to five players) are found by adding the scores earned by each member at the contest tables then creating "reward interdependence" within the practice group: the more the team members support or help each other, the more likely they are to earn points in the contest. At the end of the week, a class newsletter announces each groups' standing in the class. In addition, some comments about the winners at each table and other issues concerning the contest are discussed (Slavin, 1980; Slavin, 1991; Slavin, 1995; Slavin, \& Project, 1994).

\section{Theoretical Backgrounds and Perspectives of Cooperative Learing}

The four major theoretical backgrounds and perspectives of CL have been briefly discussed in this section. In addition to Deutsch's cooperation-competition theory discussed above, CL has its assumptions rooted in major theories. These perspectives are motivational theory's perspectives, social cohesion theory's perspectives, cognitive theory's perspectives, and developmental theory's perspectives.

Motivational Perspectives on Cooperative Learning. According to this perspective, motivation toward a task is a crucial part of the learning process. This assumes that other things are also driven by motivation. For this reason, this perspective mainly emphasizes the reward and goal structures through which students perform (Hänze \& Berger, 2007; Li, 2017; Slavin, 1987, 1995). The motivationalist perspective assumes that incentive structures in CL create a condition in which the team will be successful only when group members can achieve their own individual objectives. For this reason, to achieve their individual objectives, team members need to help each other to do whatever is helpful for group to be successful. This is realized by helping their group members exert maximum potential. Rewarding teams depending on group achievement forms an interpersonal reward structure in which team members share social reinforcers such as praise and encouragement in response to peers' task-related activities (Hänze, \& Berger, 2007; Panitz, 1999; Slavin, 2014).

Social Cohesion Perspective in Cooperative Learning. This perspective states that the effects of CL on academic performance are mediated by the a bond created within a team. It believes that group cohesion determines the success of the group's interactions. The secret of working in a group is that the students identify with each other and want each other to succeed. For the motivationalist perspective, the impetus that puts students together to work in a group is the students' motivatation learn together. On the other hand, for the social cohensive perspective the students work in groups because they care for one another or they want each other to succeed; they are interested in working together in a group because they like and respect each other and this helps them benefit from group work. The motivational and cohensive theoretical perspectives are similar in the fact that they highlight motivational rather than cognitive reasons for effectiveness of CL. The social cohesion theory perspective in CL emphasizes team-building activities in preparation for CL (Elliot et.al., 2016; Johnson \& Johnson, 2009; Slavin, 2014).

Cognitive Perspectives in Cooperative Learning. Unlike motivationalist and social cohesiveness theories that depend on motivation, the cognitive theory asserts that interaction among learners by itself enhances learner achievement because it promotes the cognitive processing of information. Goup goals are the backbones of CL developed by motivationalist theories whereas building group cohensiveness is the essence of CL methods developed by social cohensive theories. However, CL methods by cognitive theorists lack the formulation of group goals and building group cohesiveness, although they have many unique techniques for them (Allal, Chanquoy \& Largy, 2012; Slavin, 2014).

Developmental Perspectives on Cooperative Learning. Developmental perspectives assume that the interaction between students during a task that is appropriate to their developmental stage enhances their mastery of critical concepts (Slavin, 1987; Slavin, 2014). The Zone of Proximal Development (ZPD) is the gap 
between the real developmental stage and the level of potential development. This gap is filled by the guidance of adults and cooperation with team members (Vygotsky, 1978). According to Vygotsky, cooperative activities among children of similar age levels enhance development because these children operate within one another's ZPDs. According to Piaget (1926), a developmental theorist, through collaborations with peers and adults, social-arbitrary knowledge of language, values, rules, morality, and symbol systems are learned.

A nother theory related to second language learning is Gardner's Socio-educational model of second language acquisition. According to Gardner (2005), an individual's motivation for learning a second language is related to and affected by classes of variables: 1) Attitudes towards the learning situation (teachers, curriculum, school environment, etc.); 2) Integrativeness (motivation to integrate with others' cultures); 3) Instrumental orientation (learning a language for practical purposes, such as to get a job); and 4) Language anxiety and parental encouragement. Motivation and gender largely affect second language learning (Fontecha, 2010), thus second language motivation is an influencing factor in second language learning and it is very important to include second language motivation as a covariate in the data analysis (Iwaniec, 2014; Tremblay and Gardner, 1995).

\section{Method}

\section{General Background of the Research}

Initially, this study identified the underutilization of the CL principles in the application of the student-centered approach in the study area as a major problem. The general question the study was motivated to answer was, "What is the effect of CL on English language achievement if the CL approach is applied appropriately using techniques that incorporate all CL principles?" Specifically and, firstly, the study was aimed at investigating the differences between the two instructional goal structures (i.e., cooperative and competitive learning) in affecting English language achievement. Secondly, it aimed at analyzing gender, intra-gender, and inter-gender differences in English language achievement within and across the cooperative, competitive, and control group learning conditions. And thirdly, it was aimed at determining the relationship between students' motivation to learn the English language and English language achievement.

\section{Participants}

The target population of the study was Arsi Negelle Shalla Secondary School grade 9 students of the year 2011 G.C. The school is located in Ethiopia, Oromia region, West Arsi Zone, Arsi Negelle town. The total population of the study was 328 students: 167 male and 161 female. The total sample size was 120 students: 61 male and 59 female. The minimum age of the participants was 15 and the maximum was 18 . A one-way analysis of variance was conducted to identify age difference between CL and competitive learning, and the control group revealed that the age difference between the three groups was not significant, $F(2,117)=2.24, p>.05$.

During the sampling process of the participants for the study, the probability sampling design with a complex random sampling procedure followed by a stratified sampling method was used. Once the number of males and females in each stratum were identified, the sample size among strata was allocated using the following formula:

$\mathrm{n}_{\mathrm{k}}=(\mathrm{n} / \mathrm{N}) \mathrm{N}_{\mathrm{k}}$

Note: $\mathrm{nk}=$ the sample size for kth strata; $\mathrm{Nk}=$ the total population of kth strata; $\mathrm{N}=$ the total population size, and $\mathrm{n}=$ the total sample size

After determining how many members should be taken from each stratum, they were selected using simple random sampling.

\section{Sampling and Sampling Procedures}

After the pilot study, 180 students were selected using the stratified sampling formula above: 92 male and 88 female. Then the English language pre-test (43 items) was administered to these 180 students. After administering the pre-test, the papers were marked and the 180 students were categorized into high, medium, and low achieving ability levels; 1.5 standard deviations below and above the mean pre-test English language 
score were considered low and high achievers respectively and the rest were medium achievers. After the categorizing the 180 students into the three ability levels, the number of students from the three ability levels who would be included in the 120 students (25\% low achievers, $50 \%$ medium achievers, and $25 \%$ high achievers) for the main study were calculated using the stratified sampling formula. Then, the calculated number of 120 students were randomly selected from these three ability groups and remained in the study; 60 students were expelled from the study. The final step of sampling was the random assignment of the 120 students to the three ability levels. The importance of categorizing students into three ability levels is to make it suitable for the researcher to randomly select an unbiased and matching sample from the three ability levels for the experimental research.

Table 1

Assignment of Participants to the Three Groups by Gender and Ability Level

\begin{tabular}{|c|c|c|c|c|}
\hline \multirow{2}{*}{ Groups } & \multirow[t]{2}{*}{ Ability } & \multicolumn{2}{|c|}{ Gender } & \multirow{2}{*}{ Tota } \\
\hline & & Male & Female & \\
\hline \multirow[t]{4}{*}{ Cooperative Learning } & $\mathrm{H}$ & 5 & 5 & 10 \\
\hline & M & 10 & 10 & 20 \\
\hline & $\mathrm{L}$ & 5 & 5 & 10 \\
\hline & Total & 20 & 20 & 40 \\
\hline \multirow[t]{4}{*}{ Competitive Learning } & $\mathrm{H}$ & 5 & 5 & 10 \\
\hline & M & 10 & 10 & 20 \\
\hline & $\mathrm{L}$ & 5 & 5 & 10 \\
\hline & Total & 20 & 20 & 40 \\
\hline \multirow[t]{4}{*}{ Control Group } & $\mathrm{H}$ & 5 & 5 & 10 \\
\hline & M & 11 & 9 & 20 \\
\hline & $\mathrm{L}$ & 5 & 5 & 10 \\
\hline & Total & 21 & 19 & 40 \\
\hline
\end{tabular}

Note. $\mathrm{H}=$ high; $\mathrm{M}=$ medium; $\mathrm{L}=$ low

\section{Materials}

Two types of instruments were used in this study: a 43-item English language test and the 12-item mini-AMTB. All English language test items were multiple-choice items and were constructed by the author of this study. The test was prepared from the grade 9 English language textbook (unit 1 up to unit 3) - the units the students learned or covered during the semester. The reason why the English language test was constructed from the units learned in the semester was to ensure that the treatment was not using the same material that the classroom teacher was covering at the time. The test consisted of reading, grammar, dialogue, and punctuation mark items.

The 12-item mini-AMTB uses a seven-point scale. It is based on the socio-educational model (Gardner, 2005) and is used to measure the participants' degree of motivation to learn the English language. The mini-AMTB (see Gardner, 2004) is made up of 12 items that fail into six dimensions of motivational constructs: Integrativeness (item 1 up to 3), Attitude towards the Learning Situation (items 6 and 9), Motivational Intensity (items 4, 5, and 11), Instrumental Orientation (item 7), Language Anxiety (item 8 and 10), and Parental Encouragement (item 12).

Both instruments were administered in the presence of the researcher and the English language teachers of the school. Each of the English language test items was worth one point. Therefore, the highest score was 43. For the mini-AMTB, the maximum score on the scale was 84 points and the minimum was 12. A high score for the five constructs, except language anxiety, indicates a positive measure of the constructs; a high score for language anxiety measures high language anxiety.

Cronbach alpha internal consistency reliability analysis was conducted for both of the instruments. Since the Cronbach alpha reliability analysis does not work for single items, the test-retest reliability analysis was used for item 7 and item 12. The Cronbach alpha reliabilities of the English language sub-tests were: reading (.76), 
grammar (.87), dialogue (.65), and punctuation (.70). The total English language test's Cronbach alpha reliability was .91. The Cronbach alpha reliability or test-retest reliability (for single items) for the mini-AMTB sub-scales ranged from .68 (Attitude towards the Learning Situation), .74 (Integrativeness), .80 (Motivational Intensity), .90 (Instrumental Orientation), .93 (Parental Encouragement), and .93 (Language Anxiety). Gardner (1985) conducted item analysis for sub-scales of the AMTB in the French language.

The Item Discrimination Power and Item Difficulty Index (Appendix A) for the English language test were calculated. A point-biserial correlation was used to find the item discrimination power after entering the dichotomous data of the test into SPSS software. Poor distractors that were chosen by only a few students were discarded and replaced. According to Educational Data Systems ${ }^{2}$, the items with problems will always produce low point-biserial correlations. However, the accompanying p-value can be low or high. For this reason, the use of point-biserial correlation is recommended to assess item quality whereas p-values are recommended to assess item difficulty. In this study, the point-biserial correlation was used to select quality English language test items. A point-biserial value of .15 is recommended although experience shows that good items have a point-biserial value greater than or equal to .25 (Educational Data Systems, n.d). In the English language test, except item number 22, which had a point-biserial value of .18, all items had a point-biserial value of .25 and above.

The teaching materials used in this study were the grade nine English language textbook, plasma television teacher guide, and numbered cards.

\section{Research Design}

The study is a pure quantitative research and follows the positivist paradigm. The true experimental and correlational research designs were used in this study. The pre-test post-test control group experimental design using two treatment groups and one control group was applied. Cooperative and competitive groups were treatment groups whereas the individualized learning group was a control group. The experimental design used instructional goal structure (i.e., with categories of cooperative, competitive, and control group conditions) and gender (i.e., with categories of male and female) as independent variables, and the English language pre-test and the language motivation as covariates to analyze the effect of these factors on English language achievement (i.e., the dependent variable) controlling for the effect of the covariates. The reason that this design is preferred over others is that it is believed to be the best design to analyze the effect of one variable on the other controlling for the confounding variables.

On the other hand, a correlational research design, in which the aggregate measures of the mini-AMTB (i.e., Integrativeness, Motivational Intensity, Attitudes towards the Learning Situation, Instrumental Orientation, Language Anxiety, and Parental Encouragement) were correlated with English language achievement, was also used. This is to observe to what extent these measures correlate with English language learning.

\section{Data Analysis}

SPSS software version 20 was used for data analysis. To analyze the inter-gender (e.g., males and females in the CL condition and other two learning conditions) differences in English language achievement before and after treatment, a dependent sample t-test was conducted. Dependent sample t-test was used because the data were related since the students learn in the same class. The second data analysis was on the intra-gender (e.g., same-sex groups in three conditions) difference in English language achievement in the pre-test and posttest. In this analysis, the same-sex groups in the three conditions were taken as an intra-gender factor (i.e., independent variable) with categories (for example, males in CL, males in competitive learning, and males in control group) and English language achievement (i.e., the dependent variable). These variables were analyzed using a one-way analysis of variance (ANOVA) to analyze the effect of one on the other. Using the instructional goal structure and gender as independent factors, and the English language pre-test and language motivation as covariates, Analysis of Covariance (ANCOVA) was used to analyze the effect of instructional goal structure and gender on English language achievement, controlling for the covariates. Another data analysis method, the Pearson Product Moment Correlation, was used to analyze the relationship between the aggregate measures of the mini-AMTB and English language achievement.

\footnotetext{
${ }^{2}$ [Web log post]. (n.d.). http://www.eddata.com
} 


\section{Procedure}

Three weeks before the main study, the researcher visited the school, and contacted the administrators, teachers, and students. He then constructed a test from the English language course. The researcher also took the list of grade 9 students from the school office and identified the total number of males and females. During these weeks, he took a sample for the pilot study. After the pilot study, papers were marked, an item analysis was conducted, and the best English language test items were selected.

Weeks later, the researcher went to the school again and selected 180 students for the administration of the pretest. He administered the English language test (43 items) and the mini-AMTB (12 items). He scored the tests and categorized the 180 students into three ability groups.

Next, the researcher used the stratified formula and calculated the number of students from the three ability groups who would be included in the sample of 120 students for the main study. The total sample of 120 students was randomly selected from the three ability groups. Finally, the 120 students were randomly assigned to the cooperative, competitive, and control group learning conditions.

Then, the researcher taught using the three learning conditions each for one month. During the teaching period, after each presentation of a lesson to students, the researcher gave individual and group work. At the end of a week, tournaments were held. Group scores were posted for cooperative learners. Individual scores were posted for the competitive learners after each test and tournament. Tests were administered for competitive and individualized learners. Finally, the post-test was administered to the three groups and the final data analysis was conducted.

\section{Teams-Games-Tournament in This Study}

In the CL condition, students were grouped into 10 groups of four students. Each group consisted of one high achiever, two medium achievers, and one low achiever. After grouping was completed, the students were told that they were playing academic games and each student had to earn points for his/her group and the winning teams would be awarded at the end of the tournament. Generally, an orientation was given on how to work in groups at the beginning of each class.

The students were then taught according to the curriculum in the classroom and each team of students was told to study together, practice, and quiz each other after every lesson that the researcher taught. The researcher taught the day's content and gave similar tasks to be accomplished in groups after each class. The researcher prepared the questions and informed students that they should prepare for that week's tournament. At the end of each week, 10 homogenous-ability students assembled for a tournament at three tables (see Appendix B). At the start of a tournament, a student took a numbered card and the researcher asked a question. If the student answered the question correctly, they earned a point for their group. The questions the students were asked at the table were similar to the test items administered to the competitive and control groups. Each of the students was asked two questions at a table. A participant at a table could win as many cards (points) as they could win from their group. A participant got a chance to win additional cards when other participants failed to answer a question and they could manage to answer questions others failed to answer. For example, student number 1 (Appendix B) earned one additional card for his group in addition to the two cards he could win by answering his questions.

\section{Competitive teaching mode}

In this learning condition, the students were taught according to the curriculum but the researcher used a competitive teaching mode - rewarding those students who were high performing in the class and giving less attention to low achievers. At the end of a week, this class was tested and the top ten high-scoring students were announced.

\section{Control group}

In this learning condition, the students were taught according to the curriculum and the class was tested using the same test as the test the competitive group was given. However, in this condition, the students were taught 


\section{LEMECHA GELETO WARIYO}

via the individualistic learning mode in which the students were left alone to work for themselves. They were neither rewarded in groups nor individually. The researcher only told them their test results and continued teaching.

\section{Results}

\section{The Relation of Instructional Goal Structures and Gender to Students' English Language Achievement}

\section{Pre-test analysis}

In this section, the inter-gender difference is analyzed. The objective of pre-test dependent sample t-test analysis was to make sure that gender groups in a learning condition are matching in language achievement before treatment and to reasonably expect the effect of the treatment on language learning by gender in a learning condition in the post-test analysis. The dependent sample pair-wise $t$-test was conducted on pre-test data to analyze gender differences in English language achievement in a learning condition (i.e., cooperative, competitive, and control group independently) and the results are presented as follows: 1) The dependent sample $t$-test for pre-test data analysis revealed that the difference between males $(M=22.60, S D=8.75)$ and females $(\mathrm{M}=23.45, \mathrm{SD}=8.49)$ in the CL group in English language achievement was not significant, $\mathrm{t}(19)=.31$, $\mathrm{p}>.05$, two tailed; 2$)$ The dependent sample t-test for pre-test data analysis also indicated that the difference between males $(\mathrm{M}=22.15, \mathrm{SD}=8.52)$ and females $(\mathrm{M}=20.75, \mathrm{SD}=8.64)$ in competitive learning group was not significant, $\mathrm{t}(19)=-.47, \mathrm{p}>.05$, two tailed; 3) Similarly, the pre-test dependent sample t-test analysis revealed that the difference between males $(\mathrm{M}=21.37, \mathrm{SD}=8.43)$ and females $(\mathrm{M}=23.16, \mathrm{SD}=8.78)$ in the control group condition in English language achievement was not significant, $\mathrm{t}(18)=.82, \mathrm{p}>.05$, two tailed.

The one-way ANOVA pre-test intra-gender (i.e., same-sex groups in the three conditions) analysis revealed that the difference between groups of males in the three learning conditions was not significant, $F(2,58)=.02, \mathrm{p}$ > .05 . Similarly, the result was also non-significant for groups of females, $F(2,56)=.21, \mathrm{p}>.05$.

\section{The post-test analysis}

In order to test the differences in English language achievement as a result of the treatment effect in the three learning conditions, an Analysis of Covariance (ANCOVA) was conducted. The analysis of covariance, when the goal structure and gender were used as fixed factors, and the pre-test English language score and language motivation were used as covariates, revealed that the difference between the three groups in English language achievement was significant, $F(2,112)=166.70, p<.05$. However, the gender difference was not significant again in the post-test analysis of covariance, $\mathrm{F}(1,112)=.19, \mathrm{p}>.05$. From post-hoc pair-wise comparison of the Least Significant Difference analysis, it can be seen that the CL group ( $\mathrm{M}=32.45, \mathrm{SD}=7.18$ ) significantly outperformed both the competitive learning group $(\mathrm{M}=25.00, \mathrm{SD}=8.60)$ and the control group $(\mathrm{M}=26.53, \mathrm{SD}$ $=8.42), \mathrm{p}<.05$. However, the control group significantly outperformed the competitive group in this analysis.

The one-way ANOVA post-test intra-gender (i.e., same-sex groups in the three conditions) analysis revealed that the difference between groups of males in the three learning conditions in English language achievement was significant, $\mathrm{F}(2,58)=4.34, \mathrm{p}<.05$. The post-hoc Tukey HSD pair-wise comparison revealed that males in the CL group $(\mathrm{M}=32.20, \mathrm{SD}=7.56, \mathrm{n}=20)$ significantly outperformed both males in the competitive learning group $(\mathrm{M}=25.50, \mathrm{SD}=8.36, \mathrm{n}=20)$ and males in the control group $(\mathrm{M}=25.90, \mathrm{SD}=8.32, \mathrm{n}=21)$. However, the difference between males in the competitive learning group and males in the control group was not significant.

The one-way ANOVA post-test intra-gender analysis revealed that the difference between groups of females in the three learning conditions in English language achievement was significant, $F(2,56)=5.11, \mathrm{p}<.05$. The post-hoc Tukey HSD pair-wise comparison revealed that females in the CL group $(\mathrm{M}=32.70, \mathrm{SD}=6.76, \mathrm{n}=20$ ) significantly outperformed both females in the competitive learning group $(M=24.50, S D=9.01, n=20)$ and females in the control group. The difference between female competitive learners and female individualistic learners was also not significant. 
Table 2

Summary of Pair-wise t-test for Pre-test and Post-test Data

\begin{tabular}{|c|c|c|c|c|c|c|c|c|c|c|c|c|c|}
\hline \multirow[b]{2}{*}{$\begin{array}{l}\text { Dependent } \\
\text { Measure }\end{array}$} & \multirow[b]{2}{*}{ Sex } & \multicolumn{4}{|c|}{ Cooperative Learning } & \multicolumn{4}{|c|}{ Competitive Learning } & \multicolumn{4}{|c|}{ Control Group } \\
\hline & & $\mathrm{M}$ & SD & $\mathrm{N}$ & $\mathrm{t}$ & $\mathrm{M}$ & $\mathrm{SD}$ & $\mathrm{N}$ & $\mathrm{t}$ & $\mathrm{M}$ & SD & $\mathrm{N}$ & $\mathrm{t}$ \\
\hline \multirow[t]{3}{*}{ Pre-test } & $\mathrm{M}$ & 22.60 & 8.75 & 20 & \multirow{3}{*}{.31} & 22.15 & 8.52 & 20 & \multirow{3}{*}{-.47} & 22.24 & 8.53 & 21 & \multirow[t]{3}{*}{.82} \\
\hline & $\mathrm{F}$ & 23.40 & 8.46 & 20 & & 21.75 & 8.86 & 20 & & 23.16 & 8.78 & 19 & \\
\hline & Total & 23.00 & 8.50 & 40 & & 21.96 & 8.58 & 40 & & 22.67 & 8.48 & 40 & \\
\hline \multirow[t]{3}{*}{ Post-test } & $\mathrm{M}$ & 32.20 & 7.56 & 20 & \multirow{3}{*}{.21} & 25.50 & 8.36 & 20 & \multirow{3}{*}{-.28} & 25.90 & 8.32 & 21 & \multirow[t]{3}{*}{1.02} \\
\hline & $\mathrm{F}$ & 32.70 & 6.96 & 20 & & 24.50 & 9.01 & 20 & & 27.21 & 8.70 & 19 & \\
\hline & Total & 32.45 & 7.18 & 40 & & 25.00 & 8.60 & 40 & & 26.53 & 8.42 & 40 & \\
\hline
\end{tabular}

Note. $\mathrm{N}$ refers to the number of males or females in a learning condition.

$* \mathrm{p}<.05$

The dependent samples pair-wise t-test was conducted on post-test data to analyze the gender difference in English language achievement as a result of the treatment effect and the results are presented as follows: 1) The pair-wise dependent sample t-test for post-test data analysis revealed that the difference between males $(\mathrm{M}=32.20, \mathrm{SD}=7.56, \mathrm{~N}=20)$ and females $(\mathrm{M}=32.70, \mathrm{SD}=6.96, \mathrm{~N}=20)$ in English language achievement in $\mathrm{CL}$ as a result of the treatment effect was not significant, $\mathrm{t}(19)=.21, \mathrm{p}>.05$, two tailed; 2 ) The pair-wise $\mathrm{t}$-test for post-test data analysis also indicated that the difference between males $(\mathrm{M}=25.50, \mathrm{SD}=8.36, \mathrm{~N}=20)$ and females $(\mathrm{M}=24.75, \mathrm{SD}=8.86, \mathrm{~N}=20)$ in English language achievement in the competitive learning group as a result of the treatment effect was not significant, $\mathrm{t}(19)=-.28, \mathrm{p}>.05$, two tailed; and 3 ) The post-test pair-wise $t$-test analysis revealed that the difference between males $(\mathrm{M}=25.90, \mathrm{SD}=8.32, \mathrm{~N}=21)$ and females $(\mathrm{M}=27.21$, $\mathrm{SD}=8.70, \mathrm{~N}=19$, ) in English language achievement in the control group condition was not significant, $\mathrm{t}(18)=$ $1.02, \mathrm{p}>.05$, two tailed.

\section{The Relationship between English Language Learning Motivation and English Language Achievement}

The correlation between the aggregate measures of the mini-AMTB and English language achievement was found and summarized in the table below.

Table 3

Correlations between the Aggregate Measures of the Mini-AMTB English Language Achievement

\begin{tabular}{|c|c|c|c|c|c|c|c|}
\hline & 1 & 2 & 3 & 4 & 5 & 6 & 7 \\
\hline INT & - & $.70 * *$ & $.61^{* * *}$ & $.35 * *$ & $-.60 * *$ & $.47^{* * *}$ & $.77^{* * *}$ \\
\hline MI & & - & $.85^{\text {*** }}$ & $.44^{* * *}$ & $-.67 * *$ & $.50^{* * *}$ & $.83^{* * *}$ \\
\hline ALS & & & & $.48^{* * *}$ & $-.59^{* * *}$ & $.45^{* * *}$ & $.77^{* * *}$ \\
\hline IO & & & & & $-.38 * *$ & $.29^{* * *}$ & $.56^{* * *}$ \\
\hline LA & & & & & & $-.49^{* * *}$ & $-.77^{* * * *}$ \\
\hline PE & & & & & & & $.57^{* * *}$ \\
\hline Pre-test score & & & & & & & - \\
\hline
\end{tabular}

Note . INT = Integrativeness; MI = Motivational Intensity; ALS = Attitudes towards the Learning Situation; IO = Instrumental Orientation; LA = Language Anxiety; PE = Parental Encouragement

$* * \mathrm{p}<.01$, two tailed; $\mathrm{N}=120$

The analysis revealed that all of the correlations between the aggregate measures of the mini-AMTB and English language achievement were significant at .01 levels. The correlation for the five dimensions of the mini-AMTB [ i.e., Integrativeness, $r(118)=.77, \mathrm{p}<.01$; Motivational Intensity, $\mathrm{r}(118)=.83 . \mathrm{p}<.01$; Attitudes towards the Learning Situation, $\mathrm{r}(118)=.76, \mathrm{p}<.01$; Instrumental Orientation, $\mathrm{r}(118)=.56, \mathrm{p}<.01$; and Parental Encouragement, $\mathrm{r}(118)=.57, \mathrm{p}<.01]$ were positive; however, the correlation was negative for Language Anxiety, 
$r(118)=-.77, p<.01$. The highest positive correlation was observed for Motivational Intensity and the lowest positive correlation was observed for Instrumental Orientation. Studies have reported different findings on the role of the specific aggregate measures of the AMTB on second language learning.

Regarding foreign language learning motivation, Gholami, Allahyar, and Rafik-Galea (2012) reported that the dominant motivational construct among high school students was instrumental orientation. They also reported that high-achieving students were more integratively motivated than low achievers. Gardner (2012) also reported that the correlations of the integrative motivation sub-items score with English grades showed that the aggregate score was a more consistent correlate across samples than the integrative motivation subitems scores themselves. Similar to this study, Gardner also found that scores in the English language at the end of the academic year were significantly and positively correlated with motivation and integrativeness, and negatively and significantly correlated with language anxiety. Iwaniec (2014) also reported that the role of parental encouragement and language learning anxiety was limited. More interestingly, a recently published book by Lamb (2019) discussed the main theoretical approaches to language learning motivation and presented ways in which motivation theory has been applied in practice,. It showcased examples of motivation research in particular contexts and with particular types of language learners.

\section{Discussion}

Consistent with previous studies, CL had significantly and positively affected students' English language achievement. Compared to the other two learning modes, the positive effects of CL dominated the literature. Numerous studies on CL state that CL promotes high achievement; retention and transfer of knowledge gained through learning; the long-lasting implementation of knowledge; the internalization of values, attitudes, and behavior; advancing teachers' professional identity; and participation and inclusion in the community of practice (Johnson \& Johnson, 2017). A meta-analysis by Johnson, Johnson, Roseth, and Shin (2014) assessed the degree to which achievement was positively correlated with motivation and revealed that those factors related with positive interdependence resulted in higher motivation and performance than those related to negative or no interdependence conditions. A more recent study in Ethiopia by Molla and Muche (2018) also found a positive impact of CL on student learning. CL had positively and significantly affected reading and vocabulary learning (Zarei, 2012). A more recent study by Alghamdy (2019) reported that CL in language classrooms enhanced students' English language skills, promoted positive relationships among learners, helped learners play different roles, promoted oral presentation skills, and built students' self-confidence.

On the other hand, some studies reported the effect of the TGT on English language achievement and motivation towards the language. The TGT significantly and positively affected maths achievement more than a traditional method (Salam, Hossain, \& Rahman, 2015). Nasution (2018) also found a significant effect of the TGT on the vocabulary learning of grade 10 students. Learning motivation and efficiency can be enhanced through educational games (Liu \& Chen, 2013). CL positively affects both the achievement and motivation of students towards learning (Johnson, Johnson, Roseth, \& Shin, 2014). More recent studies by Fauzi, Buhun, and Purwadi (2019); Silitonga and Wu (2019); and Artha, Syam, and Priambodo (2020) reported the significant positive effect of TGT CL on both foreign learning achievement and motivation.

Additionally, the finding of this study showed the absence of gender difference in English language achievement, contrary to previous studies (Chan, 2018; Nyikos, 1990; Rua; 2006; Schmenk, 2004; Tong, Irby, Lara-Alecio, Yoon, \& Mathes, 2010; Van der Slik, Van Hout, and Schepens; 2015). The gender difference was not significant both within and between the conditions of learning in this study. Although few studies have been conducted on the gender difference in language performance by the learning mode conditions, Gillies and Ashman (1995) asserted that, from learning in gender-balanced, mixed-ability CL groups, high, medium, and low-ability students all benefited academically. On the other hand, Nawaz, Hussain, and Javed (2011) found that the CL method was found to be more effective than the lecture method in enhancing the academic achievement and academic self-efficacy of the students. Another study by Ghanbari and Samar (2016) found that the heterogeneity of the second language learning groups did not bring about a significant effect between the groups' language achievement whereas gender difference in the language achievement existed between groups. 
Moreover, 'Which learning mode is significantly favored by males and females?' was one of the research questions in this study. An intra-gender comparison revealed the presence of differences between groups of females in the three learning conditions. A group of females in the CL condition significantly outperformed a group of females in the competitive learning condition, showing no significant difference with a group of females in the control group. The group of female competitive learners also did not show a significant difference with the control group in English language achievement. In the case of males, the group of males in the CL condition significantly outperformed both the group of males in the competitive learning condition and the group of males in the control group. However, there was no significant difference between the competitive learner males and the control group males. This finding reveals that the difference in English language achievement between groups of students of the same sex occurred as a result of the learning mode differences. In other words, the intra-gender and inter-gender language achievement comparison revealed that the difference did not occur as result of the gender difference but occurred as a result of learning mode differences. In the case of intergender comparison, no difference was observed; however, in the case of intra-gender comparison, the difference between groups of students of the same sex across the three learning conditions was significant. Surprisingly, a myriad of research findings support the effectiveness of CL, especially for females (Hossain, Tarmizi, Aziz, \& Nordin, 2013; Rodger, Murray, \& Cummings, 2007; Wang, 2012) and for both sexes (Bilen \& Tavil 2015; Esiobu, 2011).

Generally, the study revealed that the CL mode is more favored (i.e., as its impact on the achievement of both sexes showed) by both sexes than competitive learning mode. However, contrary to the previous research findings cited in the previous paragraph, the study revealed that males preferred the CL mode than females as the males in the CL condition outperformed males in both competitive and control group conditions, whereas cooperative learner females outperformed on only female competitive learners.

\section{The Researcher's Own Experiences on the Implementation of Cooperative Learning: Challenges}

The researcher implemented the Teams-Games-Tournament and Student Teams Achievement Divisions in his teaching. The challenges came from students and local classroom conditions such as class size and time constraints as well as the curriculum.

For instance, high-achieving students resisted accepting the low achieving students' contributions (individual accountability) to the group task. A study by Alghamdy (2019) also found this problem. This problem happens when, in Student Teams Achievement Divisions for example, all group members sit for a test after studying in groups for days and the instructor marks the individual tests to sum up the individual contributions to the group. At this time, the high-achieving students argue that their total group result does not represent them and is not fair. For this reason, most of the time, high-achieving students want to do all the group assignments by themselves without including the contributions of all the group members.

The large class sizes and unsuitable classrooms are also problems for managing group discussions as a part of structured CL. Also, where there are no clear guidelines and time allocation for implementation of the structured CL in the curriculum, it took extra time for the researcher to adjust his methods and procedures to fit the situation.

The next issue of this study was the association between language motivation and English language achievement. The correlations of the five constructs of the mini-AMTB with English language achievement were positive and significant. However, the correlation for Language Anxiety was negative and significant. This finding is similar to the previous study conducted by Gardner (2005) in Croatia, Poland, Romania, and Spain that found positive correlations between these five constructs of the AMTB and student grades and a negative correlation with Language Anxiety in most cases. Both language achievement and attitudes toward the language improved in CL (Bilen \& Tavil, 2015). Azizinezhad, Hashemi, and Darvishi (2013) and Obinna-Akakuru, Onah, and Opara (2015) found that CL enhanced oral communicative competence and English as a foreign language learning motivation. Other studies discussed gender-based motivation towards the second language. For instance, Park and French's (2013) study results indicated that females reported higher language anxiety levels compared to males. Chan's (2018) study reported that female students were more positively oriented towards native speaker pronunciation and tended to adopt it as their teaching model and learning target. Chan also stated that female students had greater confidence than males in their ability to understand English pronunciation. Wang (2012) 
reported that CL classes improved achievement motivation among female college students. Female students' integrative motivation and attitudes towards the English language are higher than male students (Al Harthy, 2017). Generally, these findings report that CL enhances females' language learning motivation than males' language learning motivation.

The teaching period used to observe the effects of implementing the teaching methods mentioned lasted only one month because of time and financial constraints and this can be one limitation. Future studies might be invited to take a longer time to obtain stronger results.

\section{Implications}

The findings of this study can make contributions to the language curriculum. When strong language performance based on the utilization of CL is desired, the utilization of CL principles and appropriately using effective CL techniques (e.g., TGT in this study) are more fruitful. Especially, in Ethiopian schools' language classrooms where the teachers show a lack of knowledge in how to use CL methods, the introduction of different CL guidelines and techniques are more important. It is believed that when CL techniques and principles are applied by trained teachers in a CL classroom, the maximum benefit from the method is expected. Misuse of the method is the problem in Ethiopian classrooms and this study will help to improve the problem.

Gender-based individual differences in the preferred learning approach is an important issue that language curriculum specialists should pay due attention to and this study opens the way for future empirical research. Firstly, the study of gender differences in language learning locally should be compared with findings from another part of the world. This helps to identify what local factors are pulling the sexes behind in learning. Secondly, when designing a non-gender-biased curriculum, it is important to study how both sexes are similar and different in the ways they learn.

The issue of language motivation raised in this study is also something new that was missing in Ethiopian language research. It is believed that language motivation serves as fuel for learning a language and this study opens the gate for future research in the Ethiopian context. In addition, the idea that the methods of teaching and learning themselves ought to be those that can trigger motivation towards the learning (i.e., the role of structured CL) has been discussed in this study and the researcher believes that this study shows directions for curriculum designers and teachers in the subject area. The careful incorporation of the CL models in the Ethiopia English language curriculum is also recommended.

Its implication for teacher education is: 1) Teacher training has to include these methods as well as procedures that the teachers can easily apply; and 2) The mechanisms by which teachers teach the groups of students how to work in groups, assure individual accountability, and apply other CL principles should be included in teacher training.

Finally, the researcher encourages future local and international researchers to conduct further studies on other CL models such as Student Teams Achievement Divisions, Learning Together, Academic Controversy, Group Investigation, Teams Assisted Individualization, and Cooperated Integrated Reading Composition.

\section{Conclusion}

Based on the findings of this study, the following conclusions can be drawn: 1) CL mode, when it is applied in English language learning classrooms with effective CL techniques, can result in higher student English language achievement than the competitive learning mode; 2) The significant gender difference in English language achievement was not supported by the findings of this study when the two sexes are compared after teaching in classes of mixed ability and mixed gender composition using cooperative and competitive learning condition treatment conditions and using individualistic learners as a control group; 3) The significant difference in English language achievement between the two sexes within a learning condition group was not supported by the findings of this study; 4) CL mode was found to be effective for both sexes, but found to be more 
effective for males; and 5) English language achievement was significantly and positively correlated with the five dimensions of the mini-AMTB, while it produced a significant negative correlation with Language Anxiety.

\section{Acknowledgments}

I would like to thank Addis Ababa University for funding this work. My gratitude also goes to Dr. Girma Lemma for advising me throughout this study. I thank Arsi Negelle Shalla high school administrators, teachers, and students for their active cooperation during this study.

\section{References}

Alghamdy, R. Z. (2019). EFL learners' reflections on cooperative learning: Issues of implementation. Theory and Practice in Language Studies, 9(3), 271-277. https://doi.org/10.17507/tpls.0903.03

$\mathrm{Al}$ Harthy, S. R. (2017). English language motivation between gender and cultures. Journal of Educational and Social Research, 7(2), 123-132. https://doi.org/10.5901/jesr.2017.v7n2p123

Allal, L., Chanquoy, L., \& Largy, P. (2012). Revision Cognitive and Instructional Processes: Cognitive and Instructional Processes. Springer Science \& Business Media.

Alsheikh, N. \& Elhoweris, H. (2011). United Arab Emirates (UAE) high school students' motivation to read in English as a foreign language. International Journal of Language Studies (ILLS), 5(4), 53-68.

Artha, A. A., Syam T, A. R., \& Priambodo, A. (2020). The application of teams games tournament (TGT) and teaching game for understanding (TGfU) learning models on learning motivation and Volley Ball passing skills. Budapest International Research and Critics in Linguistics and Education (BirLE) Journal, 3(1), 46-53. https://doi.org/10.33258/birle.v3i1.751

Ayele, Z.A. \& Olamo, T.G. (2019). The practices, challenges and opportunities of cooperative learning at Hawassa University - Ethiopia. IOSR Journal of Humanities And Social Science (IOSR-JHSS), 24 (3), 15-27.

Azizinezhad, M., Hashemi, M., \& Darvishi, S. (2013). Application of cooperative learning in EFL classes to enhance the students' language learning. Procedia - Social and Behavioral Sciences, 93, 138-141. https://doi. org/10.1016/j.sbspro.2013.09.166

Baloche, L., \& Brody, C. M. (2017). Cooperative learning: exploring challenges, crafting innovations. Journal of Education for Teaching, 43(3), 274-283. https://doi.org/10.1080/02607476.2017.1319513

Bilen, D., \& Tavil, Z. M. (2015). The effects of cooperative learning strategies on vocabulary skills of 4th grade students. Journal of Education and Training Studies, 3(6), 151-165. https://doi.org/10.11114/jets.v3i6.1062

Boling, N. C., \& Robinson, D. H. (1999). Individual study, interactive multimedia, or cooperative learning: Which activity best supplements lecture-based distance education? Journal of Educational Psychology, 91(1), 169174. https://doi.org/10.1037//0022-0663.91.1.169

Çelik, S., Aytın, K., \& Bayram, E. (2013). Implementing cooperative learning in the language classroom: Opinions of Turkish teachers of English. Procedia - Social and Behavioral Sciences, 70, 1852-1859. https://doi. org/10.1016/j.sbspro.2013.01.263

Chan, J.Y.H (2018). Gender and attitudes towards English varieties: Implications for teaching English as a global language. System, 76, 62-79.

Desta, D., Chalchisa, D., Mulat, Y., Berihum, A. \& Tesera, A. (2009). Enhancing active learning through self- andpeer reflections: the case of selected schools in Ethiopia. Journal of International Cooperation in Education, 12(1), 71-87.

Deutsch M. (2015). Cooperation, Competition, and Conflict. In M. Deutsch (Ed.), A pioneer in developing peace Psychology (pp. 47-70). Springer. https://doi.org/10.1007/978-3-319-15440-4_3

Deutsch, M. (2011). Cooperation and Competition. Conflict, Interdependence, and Justice, 23-40. https://doi. org/10.1007/978-1-4419-9994-8_2

Deutsch, M. (1949). A Theory of co-operation and competition. Human Relations, 2(2), 129-152. https://doi. org/10.1177/001872674900200204

Elliot, A. J., Aldhobaiban, N., Kobeisy, A., Murayama, K., Gocłowska, M. A., Lichtenfeld, S., \& Khayat, A. (2016). Linking social interdependence preferences to achievement goal adoption. Learning and Individual Differences, 50, 291-295. https://doi.org/10.1016/j.lindif.2016.08.020 


\section{LEMECHA GELETO WARIYO}

Esiobu,G.O.(2011).Researchachievinggenderequityinscienceclass shift fromcompetitiontocooperativelearning. Multicultural Education \& Technology Journal, 5(4), 244-257. https://doi.org/10.1108/17504971111185081

Fauzi, M. F., Buhun, M. F., \& Purwadi, A. (2019).The influence of teams games tournament (TGT) toward students' interest in Arabic language learning. Izdihar : Journal of Arabic Language Teaching, Linguistics, and Literature, 2(2),135-148. https://doi.org/10.22219/jiz.v2i2.9986

Feery, K. (2008).Current perspectives on the role of gender in second language acquisition (SLA) research.The ITB Journal, 9(1), 21-51.

Ferguson-Patrick, K. (2016). The importance of teacher role in cooperative learning: The effects of high-stakes testing on pedagogical approaches of early career teachers in primary schools. Education 3-13, 46(1), 89-101. https://doi.org/10.1080/03004279.2016.1189946

Fontecha, A. F. (2010). Gender and motivation in EFL vocabulary production. In R. M. J. Catalán (Ed.), Gender perspectives on vocabulary in foreign and second languages (pp. 93-116). Palgrave Macmillan.https://doi. org/10.1057/9780230274938_5

Gardner, R. C. (1985). Social Psychology and second language learning: The role of attitudes and motivation. Hodder Arnold.

Gardner, R.C. (1985). The attitude/Motivation Test Battery: Technical report. University of Western Ontario, Canada. http://publish.uwo.ca/ gardner/docs/AMTBmanual.pdf

Gardner, R. C. (2004). Attitude / Motivation Test Battery. International AMTB research project (English version). The University of Western Ontario, Canada. http://publish.uwo.ca/ Gardner/docs/englishamtb.pdf

Gardner, R. C. (2005). Integrative motivation and second language acquisition. Canadian Association of Applied Linguistics: Association of Joint Plenary Talk. Social Sciences and Humanities Research Council of Canada.

Gardner, R. C. (2012). Integrative motivation and global language (English) acquisition in Poland. Studies in Second Language Learning and Teaching, 2(2), 215-226. https://doi.org/10.14746/ssllt.2012.2.2.5

Gezahagn, G. (2003). In-service English language teachers' perceptions of the factors that influence the implementation of group work and activities in ELT classes. Ethiopian Journal of Education, 23, 103-126.

Ghanbari, N., \&Samar, R.G. (2016).Grouping strategies and writing achievement in cooperative learning. Journal of Applied Linguistics and Language Research, 3(7), 85-97.

Ghodbane, T., \& Hamzaoui El Achachi, H. (2019). Narrowing the achievement gap between EFL students in oral expression through cooperative learning. Arab World English Journal, 10(2), 365-378. https://doi. org/10.24093/awej/vol10no2.28

Gholami, Z., Allahyar and Rafik-Galea (2012). Integrative motivation as an essential determinant of achievement: A case of EFL high school students. World Applied Sciences Journal, 17(11), 1416-1424.

Gillies, R. M. (2016). Cooperative learning: Review of research and practice. Australian Journal of Teacher Education, 41(3), 39-54. http://dx.doi.org/10.14221/ajte.2016v41n3.3

Gillies, R. M., \& Ashman, A. F. (1995).The effects of gender and ability on students' behaviours and interactions in classroom-based work groups. British Journal of Educational Psychology, 65(2), 211-225. https://doi. org/10.1111/j.2044-8279.1995.tb01143.x

Gillies, R. M., Ashman, A., \& Terwel, J. (2007). The Teacher's role in implementing cooperative learning in the classroom. Springer Science \& Business Media.

Hänze, M. E., \& Berger, R. (2007). Cooperative learning, motivational effects, and student characteristics: An experimental study comparing cooperative learning and direct instruction in 12th grade physics classes. Learning and Instruction, 17(1), 29-41. https://doi.org/10.1016/j.learninstruc.2006.11.004

Hossain, A., Tarmizi, R.A., Aziz, Z., \& Nordin, N. (2013). Group learning effects and gender differences in mathematical performance. Croatian Journal of Education, 15(2), 41-67.

Iwaniec, J. (2014). Motivation of pupils from southern Poland to learn English. System, 45, 67-78. https://doi. org/10.1016/j.system.2014.05.003

Johnson, D. W., \& Johnson, F. (2013). Joining together: Group theory and group skills (11th ed.). Allyn \& Bacon

Johnson, D. W., Johnson, R. T., \& Holubec, E. J. (2013). Cooperation in the classroom (9th ed.). Interaction Book Company.

Johnson, D. W., \& Et al. (1981). Effects of cooperative, competitive, and individualistic goal structures on achievement: A meta-analysis. Psychological Bulletin, 89(1), 47-62. https://doi.org/10.1037//00332909.89.1.47

Johnson, D. W., \& Johnson, R. T. (1974). Instructional goal structure: Cooperative, competitive, or individualistic. Review of Educational Research, 44(2), 213-240. https://doi.org/10.2307/1170165

Johnson, D. W., \& Johnson, R. T. (1974). Instructional goal structure: Cooperative, competitive, or individualistic. Review of Educational Research, 44(2), 213-240. https://doi.org/10.2307/1170165 
Johnson, D. W., \& Johnson, R. T. (2009). An educational psychology success story: Social interdependence theory and cooperative learning. Educational Researcher, 38(5), 365-379. https://doi.org/10.3102/0013189x09339057

Johnson, D. W., \& Johnson, R. T. (2017). The use of cooperative procedures in teacher education and professional development. Journal of Education for Teaching, 43(3), 284-295. https://doi.org/10.1080/02607476.2017.132 8023

Johnson, D. W., Johnson, R. T., Johnson, J., \& Anderson, D. (1976). Effects of cooperative versus individualized instruction on student prosocial behavior, attitudes toward learning, and achievement. Journal of Educational Psychology, 68(4), 446-452. https://doi.org/10.1037//0022-0663.68.4.446

Johnson, D. W., Johnson, R. T., Roseth, C., \& Shin, T. S. (2014). The relationship between motivation and achievement in interdependent situations. Journal of Applied Social Psychology, 44(9), 622-633. https://doi. org/10.1111/jasp.12280

Jolliffe, W. (2015). Learning to learn together: Cooperation, theory and practice. Education 3-13, 43(1), 1-4. https://doi.org/10.1080/03004279.2015.992617

Kumar, M.K. (2017). Challenges of implementing student-centered strategies in classrooms. International Research Journal of Engineering and Technology, 3(12), 1224-1227

Kyndt, E., Raes, E., Lismont, B., Timmers, F., Cascallar, E., \& Dochy, F. (2013). A meta-analysis of the effects of face-to-face cooperative learning. Do recent studies falsify or verify earlier findings? Educational Research Review, 10, 133-149. https://doi.org/10.1016/j.edurev.2013.02.002

Lamb, M. (2019). The Palgrave handbook of motivation for language learning. Springer Nature.

$\mathrm{Li}, \mathrm{K}$. (2017). Motivational regulation and L2 Learning. In Motivational Regulation in Foreign Language Learning. Palgrave Macmillan. https://doi.org/10.1057/978-1-349-93118-7_3

Liu, E. Z., \& Chen, P. (2013). The effect of Game-Based Learning on students' learning performance in science learning - A case of "Conveyance Go". Procedia - Social and Behavioral Sciences, 103, 1044-1051. https://doi. org/10.1016/j.sbspro.2013.10.430

Lopez-Rua, P (2006). The sex variable in foreign language learning: An integrative approach. PORTA LINGUARUM, 6, 99-114.

Lucha, Z.T., \& Bongase, T.M. (2015).A Study on the practices of cooperative language learning method: Enango high school grade 9 in focus.Science, Technology and Arts Research Journal, 4(2), 278-287. https://doi.org/ http://dx.doi.org/10.4314/star.v4i2.39

Mady, C., \& Seiling, A. (2017). The coupling of second language learning motivation and achievement according to gender. Theory and Practice in Language Studies, 7(12), 1149. https://doi.org/10.17507/tpls.0712.01

Masgoret, A., \& Gardner, R. C. (2003). Attitudes, motivation, and second language learning: A meta-analysis of studies conducted by Gardner and associates. Language Learning, 53(1), 123-163. https://doi.org/10.1111/14679922.00212

McCafferty, S. G., Jacobs, G. M., \& Iddings, A. C. (2006). Cooperative learning and second language teaching. Cambridge University Press.

Moges, B. (2019). Practices and challenges of cooperative learning in selected college of Arsi University: As a ootivational factor on enhancing students' learning. Universal Journal of Psychology 7 (1), 1 - 17. https://doi. org/ 10.13189/ujp.2019.070101.

Mohammadjani , F. \& Tonkaboni , F. (2015). A comparison between the effect of cooperative learning teaching method and lecture teaching method on students' learning and satisfaction level. International Education Studies, 8(9), 107-112. https://doi.org/ doi:10.5539/ies.v8n9p107

Molla, E., \& Muche, M. (2018). Impact of cooperative learning approaches on students' academic achievement and laboratory proficiency in Biology subject in selected rural schools, Ethiopia. Education Research International, 2018, 1-9. https://doi.org/10.1155/2018/6202484

Nasution, M. (2018). The effect of Team Games Tournament (TGT) method toward vocabulary mastery at the tenth grade students of high school 1 Padangsidimpuan. IOP Conference Series: Earth and Environmental Science, 175, 1-5. https://doi.org/10.1088/1755-1315/175/1/012087

Nawaz, Q., Hussain, L. \& Javed, M. (2011). A gender based comparative study of cooperative learning and lecture demonstration method on the academic achievement and academic self-concept at elementary school level. Pakistan Journal of Education, 28(2), 47-60.

Nyikos, M. (1990). Sex-related differences in adult language learning: Socialization and memory factors. The Modern Language Journal, 74(3), 273-287. https://doi.org/10.2307/327624

Obinna-Akakuru, A.U., Onah, T.A., \& Opara, D.C. (2015). Cooperative learning and student's academic achievement in English language in Imo State, Nigeria. IOSR Journal of Research \& Method in Education, 5(3), 26-29 


\section{LEMECHA GELETO WARIYO}

Owens, L., \& Straton, R. G. (1980).The development of a co-operative, competitive, and individualised learning preference scale for students. British Journal of Educational Psychology, 50(2), 147-161. https://doi. org/10.1111/j.2044-8279.1980.tb02440.x

Owens, L., \& Straton, R. G. (1980). The development of a co-operative, competitive, and individualised learning preference scale for students. British Journal of Educational Psychology, 50(2), 147-161. https://doi. org/10.1111/j.2044-8279.1980.tb02440.x

Oxford, R. L. (1997). Cooperative learning, collaborative learning, and interaction: Three communicative strands in the language classroom. The Modern Language Journal, 81(4), 443-456. https://doi. org/10.1111/j.1540-4781.1997.tb05510.x

Panitz, T. (1999). The motivational benefits of cooperative learning. New Directions for Teaching and Learning, 1999(78), 59-67. https://doi.org/10.1002/tl.7806

Park, G., \& French, B. F. (2013). Gender differences in the foreign language classroom anxiety scale. System, 41, 462-471.

Pedersen, J. E., \& Digby, A. D. (2014). Secondary schools and cooperative learning: Theories, models, and strategies. Routledge.

Peldon, D., \& Chalermnirundorn, N. (2018). The effects of cooperative learning strategies on sixth grade Bhutanese students' learning achievement and satisfaction in social studies class. St.Theresa Journal of Humanities and Social Sciences, 4(2), 1-29.

Piaget, J. (1926). The language and thought of the child. Harcourt Brace.

Reda, W. N., \& Hagos, G. T. (2015). The practices of student network as cooperative learning in Ethiopia. Africa Education Review, 12(4),696-712. https://doi.org/10.1080/18146627.2015.1112162

Rodger, S., Murray, H.G., \& Cummings, A.L. (2007). Gender differences in cooperative learning with university students. Alberta Journal of Educational Research, 53(2), 157-173.

Salam, A., Hossain, A., \& Rahman, S. (2015). The effect of using Teams Games Tournaments (TGT) cooperative technique for learning mathematics in secondary schools of Bangladesh. REDIMAT, 4(3), 271-287. https:// doi.org/10.17583/redimat.2015.1519

Schmenk, B. (2004). Language learning: A feminine domain? The role of stereotyping in constructing gendered learner identities. TESOL Quarterly, 38(3), 514-524. https://doi.org/10.2307/3588352

Serbessa, D.D. (2006). Tension between traditional and modern teaching-learning approaches in Ethiopian primary schools. Journal of International Cooperation in Education, 9(1), 123-140.

Sharan, S. (1980). Cooperative learning in small groups: recent methods and effects on achievement, attitudes, and ethnic relations. Review of Educational Research, 50(2), 241 - 271. https://doi.org/10.2307/1170146

Siciliano, J. I. (2001). How to incorporate cooperative learning principles in the classroom: It's more than just putting students in teams. Journal of Management Education, 25(1), 8-20. https://doi. org/10.1177/105256290102500103

Silitonga L.M., Wu TT. (2019). Increasing students' interest and learning achievement using cooperative learning (Students Team Achievement Division) through Edmodo. In L. Rønningsbakk, T. Wu, F. Sandnes \& Y. Huang (Eds.), Innovative technologies andlLearning. Lecture notes in Computer Science (vol. 11937, pp. 3-13). Springer. https://doi.org/10.1007/978-3-030-35343-8_1

Slavin, R. E. (1991). Student team learning: A practical guide to cooperative learning. NEA.

Slavin, R. E. (1994). Using student team learning (2 $\left.{ }^{\text {nd }} e d.\right)$. Johns Hopkins University.

Slavin, R. E. (1995). Cooperative learning: Theory, research, and practice ( $\left.2^{\text {nd }} e d.\right)$. Pearson College.

Slavin, R. E. (2014). Making cooperative learning powerful. Educational Leadership, 72(2), 22-26.

Slavin, S. (1980). Cooperative learning. Review of educational research,50(2), 315-342. https://doi. org/10.2307/1170149

Slavin, R.E.(1987). Developmental and motivational perspectives on cooperative learning: A reconciliation. Child Development, 58(5), 1161-1167. https://doi.org/10.1111/j.1467-8624.1987.tb01449.x

Slavin, R. E. (2013). Effective programmes in reading and mathematics: Lessons from the Best Evidence Encyclopaedia1. School Effectiveness and School Improvement, 24(4), 383-391. https://doi.org/10.1080/0924 3453.2013.797913

Sunderland J. (2010). Theorizing gender perspectives in foreign and second language learning. In R. M. J. Catalán. (Ed.), Gender perspectives on vocabulary in foreign and second languages (pp. 1-19). Palgrave Macmillan. https:// doi.org/10.1057/9780230274938_1

Teimouri, Y., Goetze, J., \& Plonsky, L. (2019). Second language anxiety and achievement. Studies in Second Language Acquisition, 41(2), 363-387. https://doi.org/10.1017/s0272263118000311

Tercanlioglu, L. (2004). Achievement goal theory: A perspective on foreign-language-learners' motivation. TESL 
Canada Journal, 21(2),34-49. https://doi.org/10.18806/tesl.v21i2.173

Tirussew, T., Amare, A., Jeilu, O. Tassew, W., Aklilu, D., \& Berhannu, A. (2018). Ethiopian education development roadmap (2018-30): An integrated executive summary: Draft for discussion. https://planipolis.iiep.unesco. org/en/2018/ethiopian-education-development-roadmap-2018-30-integrated-executive-summary-draftdiscussion

Tong, F., Irby, B., Lara-Alecio, R., Yoon, M., \& Mathes, P. (2010). Hispanic English learners' responses to longitudinal English instructional intervention and the effect of gender: A multilevel analysis. The Elementary School Journal, 110(4), 542-566. https://doi.org/10.1086/651195

Tremblay, P. F., \& Gardner, R. C. (1995). Expanding the motivation construct in language learning. The Modern Language Journal, 79(4), 505-518. https://doi.org/10.2307/330002

van der Slik, F.W.P., van Hout R.W.N.M., \& Schepens , J.J. (2015). The gender gap in second language acquisition: Gender differences in the acquisition of Dutch among immigrants from 88 countries with 49 mother tongues. PLoS ONE, 10(11), 1-22. https://doi.org/10.1371/journal.pone.0142056

Vygotsky, L. S. (1978). Mind in society. Harvard University Press.

Johnson, W. D., \& Johnson, T. R. (2018). Cooperative learning: The foundation for active learning. In M.B. Silvo (Ed.), Book active learning. IntechOpen. https://doi.org/10.5772/intechopen.81086

Wang, M. (2012). Effects of cooperative learning on achievement motivation of female university students. Asian Social Science, 8(15), 108-114. https://doi.org/10.5539/ass.v8n15p108

Yager, S., Johnson, D. W., \& Johnson, R. T. (1985). Oral discussion, group-to-individual transfer, and achievement in cooperative learning groups. Journal of Educational Psychology, 77(1), 60-66. https://doi.org/10.1037//00220663.77.1.60

Yalew, E. (2004). Teachers' beliefs, knowledge, and practice of learner-centered approach in schools of Ethiopia. The Ethiopian Journal of Education, 24, 17-41. http://ejol.aau.edu.et/index.php/EJE/article/view/97

Yayo, B. (2013). Teachers' knowledge, attitude and practice of cooperative learning the case of Alamata Town administration second cycle primary schools [Unpublished Master's Thesis]. Addis Ababa University.

Zarei, A. A. (2012). The effects of STAD and CIRC on L2 reading comprehension and vocabulary learning. Frontiers of Language and Teaching, 3, 161-173.

Zareian, G. and Jodaei, H.(2015). Motivation in second language acquisition: A State of the art article. International J. Soc. Sci. \& Education,5(2), 295-308

Zhang, Y. (2010). Cooperative language learning and foreign language learning and teaching. Journal of Language Teaching and Research, 1(1), 81-83. https://doi.org/10.4304/jltr.1.1.81-83 


\section{LEMECHA GELETO WARIYO}

\section{Appendix A}

\section{Point-biserial and p-values of the English Language Test}

\begin{tabular}{lcccccccc}
\hline Reading (1-8) & & & & & & & & \\
\hline Items & It1 & It2 & It3 & It4 & It5 & It6 & It7 & It8 \\
Point-biserial & .47 & .25 & .52 & .25 & .44 & .68 & .51 & .57 \\
p-values & .62 & .59 & .38 & .35 & .35 & .29 & .21 & .35 \\
\hline
\end{tabular}

Grammar (9-34)

\begin{tabular}{|c|c|c|c|c|c|c|c|c|c|c|c|c|c|c|c|c|}
\hline Items & It9 & It10 & It11 & It12 & It13 & It14 & It15 & It16 & It17 & It18 & It19 & It20 & It21 & It22 & It23 & It24 \\
\hline Point-biserial & .43 & .45 & .36 & .34 & .47 & .29 & .37 & .49 & .28 & .58 & .48 & .26 & .36 & .18 & .54 & .37 \\
\hline p-values & .59 & .65 & .74 & .62 & .65 & .35 & .35 & .18 & .62 & .47 & .35 & .29 & .24 & .41 & .53 & .35 \\
\hline Items & It25 & It26 & It27 & It28 & It29 & It30 & It31 & It32 & It33 & It34 & & & & & & \\
\hline Point-biserial & .46 & .45 & .63 & .57 & .36 & .32 & .24 & .67 & .28 & .57 & & & & & & \\
\hline p-values & .44 & .26 & .45 & .45 & .58 & .81 & .71 & .29 & .74 & .35 & & & & & & \\
\hline
\end{tabular}

\begin{tabular}{lllllllllll}
\hline & \multicolumn{3}{l}{ Dialogue (35-40) } & \multicolumn{4}{c}{ Punctuation (41-43) } \\
\hline Items & It35 & It36 & It37 & It38 & It39 & It40 & It41 & It42 & It43 \\
Point-biserial & .41 & .39 & .36 & .63 & .27 & .49 & .49 & .50 & .47 \\
p-values & .52 & .68 & .52 & .42 & .61 & .52 & .58 & .65 & .45 \\
\hline
\end{tabular}




\section{Appendix B}

Summary of the Tournament Procedure

\begin{tabular}{|c|c|c|c|c|c|c|c|c|}
\hline \multirow{2}{*}{ Week } & \multirow{2}{*}{ Student } & \multirow{2}{*}{ Table } & \multirow{2}{*}{ Team Number } & \multirow{2}{*}{$\begin{array}{c}\text { Ability } \\
\text { Level }\end{array}$} & \multirow{2}{*}{$\begin{array}{c}\text { Questions } \\
\text { Asked }\end{array}$} & \multicolumn{2}{|c|}{ Number of cards } & \multirow{2}{*}{$\begin{array}{l}\text { Points } \\
\text { earned }\end{array}$} \\
\hline & & & & & & Won & lost & \\
\hline \multirow[t]{10}{*}{1} & 1 & \multirow{3}{*}{1} & 5 & High & 2 & 3 & 0 & 6 \\
\hline & 2 & & 7 & High & 2 & 1 & 1 & 2 \\
\hline & 3 & & 2 & High & 2 & 2 & 0 & 4 \\
\hline & 4 & \multirow{3}{*}{2} & 4 & High & 2 & 3 & 0 & 6 \\
\hline & 5 & & 10 & High & 2 & 2 & 0 & 4 \\
\hline & 6 & & 3 & High & 2 & 1 & 1 & 2 \\
\hline & 7 & \multirow{4}{*}{3} & 6 & High & 2 & 2 & 0 & 4 \\
\hline & 8 & & 9 & High & 2 & 2 & 0 & 4 \\
\hline & 9 & & 1 & High & 2 & 3 & 0 & 6 \\
\hline & 10 & & 8 & High & 2 & 1 & 1 & 2 \\
\hline \multirow[t]{10}{*}{2} & 11 & \multirow{3}{*}{4} & 5 & Low & 2 & 1 & 1 & 2 \\
\hline & 12 & & 8 & Low & 2 & 2 & 0 & 4 \\
\hline & 13 & & 1 & Low & 2 & 3 & 0 & 6 \\
\hline & 14 & \multirow{3}{*}{5} & 10 & Low & 2 & 4 & 0 & 6 \\
\hline & 15 & & 6 & Low & 2 & 1 & 1 & 4 \\
\hline & 16 & & 3 & Low & 2 & 1 & 1 & 4 \\
\hline & 17 & \multirow{4}{*}{6} & 4 & Low & 2 & 0 & 2 & 2 \\
\hline & 18 & & 7 & Low & 2 & 1 & 1 & 2 \\
\hline & 19 & & 2 & Low & 2 & 2 & 0 & 4 \\
\hline & 20 & & 9 & Low & 2 & 4 & 0 & 6 \\
\hline \multirow[t]{10}{*}{3} & 21 & \multirow{3}{*}{7} & 7 & Medium & 2 & 1 & 1 & 4 \\
\hline & 22 & & 3 & Medium & 2 & 0 & 2 & 2 \\
\hline & 23 & & 1 & Medium & 2 & 3 & 0 & 6 \\
\hline & 24 & \multirow{3}{*}{8} & 9 & Medium & 2 & 2 & 0 & 4 \\
\hline & 25 & & 4 & Medium & 2 & 1 & 1 & 2 \\
\hline & 26 & & 8 & Medium & 2 & 3 & 0 & 6 \\
\hline & 27 & \multirow{4}{*}{9} & 6 & Medium & 2 & 0 & 2 & 2 \\
\hline & 28 & & 10 & Medium & 2 & 2 & 0 & 4 \\
\hline & 29 & & 2 & Medium & 2 & 1 & 1 & 2 \\
\hline & 30 & & 5 & Medium & 2 & 4 & 0 & 6 \\
\hline \multirow[t]{10}{*}{4} & 31 & \multirow{4}{*}{10} & 2 & Medium & 2 & 3 & 0 & 6 \\
\hline & 32 & & 7 & Medium & 2 & 1 & 1 & 2 \\
\hline & 33 & & 4 & Medium & 2 & 2 & 0 & 4 \\
\hline & 34 & & 1 & Medium & 2 & 2 & 1 & 4 \\
\hline & 35 & \multirow{2}{*}{11} & 9 & Medium & 2 & 0 & 2 & 2 \\
\hline & 36 & & 5 & Medium & 2 & 3 & 0 & 6 \\
\hline & 37 & \multirow{4}{*}{12} & 6 & Medium & 2 & 2 & 0 & 4 \\
\hline & 38 & & 3 & Medium & 2 & 1 & 1 & 2 \\
\hline & 39 & & 10 & Medium & 2 & 4 & 0 & 6 \\
\hline & 40 & & 8 & Medium & 2 & 1 & 1 & 2 \\
\hline
\end{tabular}




\section{LEMECHA GELETO WARIYO}

\section{Appendix C}

Rank of Practice Group According to the Total Scores Earned by Individual Group Members

\begin{tabular}{lc}
\hline Practice Team Group Number & Total Points Earned \\
\hline 1 & 22 \\
5 & 20 \\
10 & 20 \\
9 & 16 \\
2 & 16 \\
6 & 14 \\
8 & 14 \\
4 & 14 \\
3 & 10 \\
7 & 10 \\
\hline
\end{tabular}

